\section{Unique Cause of Ischemic Heart Disease - Hypoplastic Left Coronary Cusp Separated by Membranous Structure -}

Toshiyuki Kozai, MD; Ko Takesue, MD;

Kunpei Osaka, MD; Yusuke Yamamoto, MD

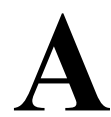
64-year-old woman was referred to Saiseikai Fukuoka General Hospital due to chest pain on effort. Her coronary risk factor was diabetes mellitus. On enhanced multi-detector row computed tomography (MDCT) the ostium of the left coronary artery (LCA) looked occluded, and the LCA was perfused by a welldeveloped collateral vessel from the right coronary artery (RCA). Invasive coronary angiogram confirmed that the LCA was perfused via the collateral vessel from the RCA, but the ostium of the LCA was patent and the left coronary cusp (LCC) was filled with retrograde LCA blood flow (Figure A). Additionally, the LCC was isolated from the original aortic cusp, and this was confirmed on aortography (Figure B), given that selective left coronary angiography was unable to be carried out. On transesophageal echocardiography the LCC was hypoplastic (Supplementary Figure 1), therefore, the aortic valve was thought to be functionally bicuspid. Surgical intervention was selected for the revascularization. On intraoperative examination, the collateral vessel from the RCA to the LCA was extremely well-developed (Supplementary Figure 2; white arrow) and the native aortic valve seemed to be bicuspid. On careful examination, however, the small LCC was found to be located underneath the non-coronary cusp and was separated by a membranous structure from the original aortic cup (Supplementary Figure 2; black arrow). The membranous structure was resected and sequential aortic valve replacement was performed. One week after surgery, LCA antegrade blood flow and disappearance of the collateral vessel from the RCA to LCA was confirmed on MDCT. The symptom was also improved. On pathology there were no specific abnormalities in the membranous structure or native aortic valves, suggesting that the etiology was congenital. The present case highlights the unique congenital cause of ischemic heart disease.

\section{Disclosures}

The authors declare no conflicts of interest.

\section{Supplementary Files}

Please find supplementary file(s);

http://dx.doi.org/10.1253/circrep.CR-18-0027

Received December 18, 2018; accepted December 18, 2018; J-STAGE Advance Publication released online January 17, 2019 Time for primary review: 1 day

Division of Cardiology, Cardiovascular and Aortic Center, Saiseikai Fukuoka General Hospital, Fukuoka, Japan

Mailing address: Toshiyuki Kozai, MD, Division of Cardiology, Fukuoka Red Cross Hospital, 3-1-1 Ohgusu, Minami-ku, Fukuoka 815-8555, Japan. E-mail: toshikoz@navy.email.ne.jp

ISSN-2434-0790 All rights are reserved to the Japanese Circulation Society. For permissions, please e-mail: cr@j-circ.or.jp

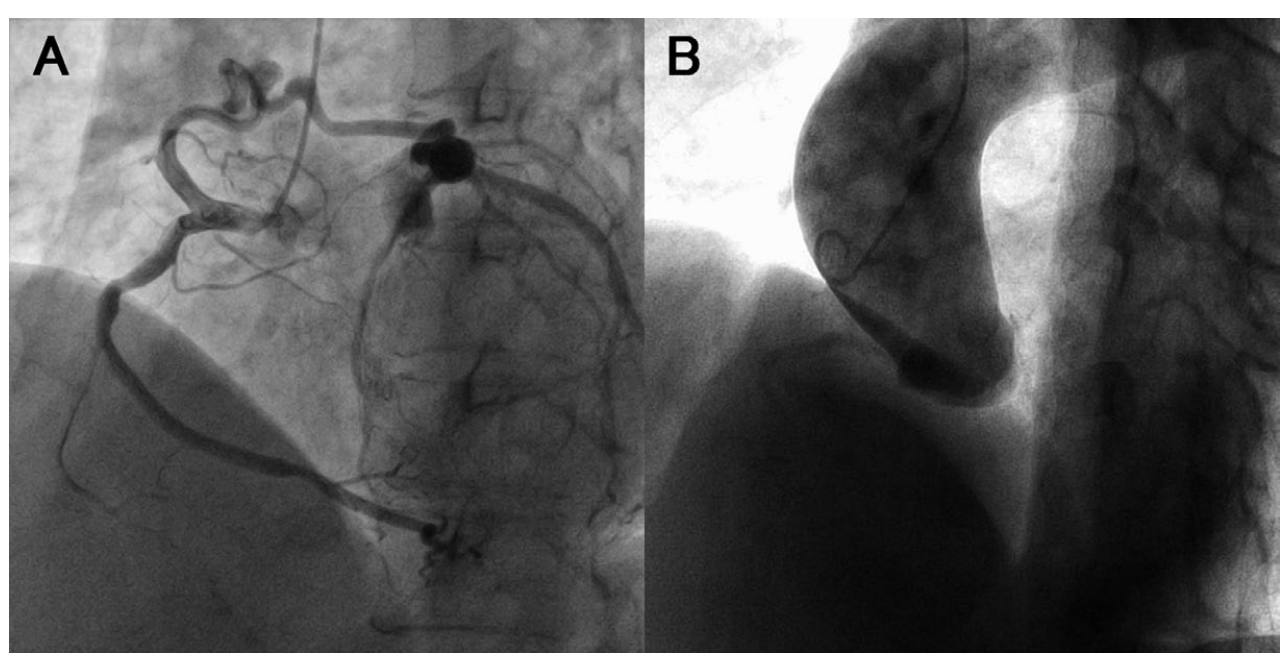

Figure. (A) Selective right coronary angiogram showed a well-developed collateral from the right coronary artery to left anterior descending coronary artery, but the ostium of the left coronary artery (LCA) was patent, and the left coronary cusp (LCC) was filled with retrograde LCA blood flow. (B) Aortography confirmed that the LCC was isolated from the original aortic cusp. 